\title{
Tradition, Change, and Continuity in Chinese Theatre in the Last Hundred Years: In Commemoration of the Spoken Drama Centenary
}

\author{
Colin Mackerras
}

\begin{abstract}
Commemorating the centenary of the spoken drama's introduction into China in 1907, the essay takes up several major themes in Chinese theatre over the last hundred years, such as its political and social implications and the tension between foreign and indigenous influences. The essay argues that drama in China during these years can be viewed largely as a microcosm of history, with politics having more impact on drama than the other way around. It also argues that change outweighs continuity, with foreign influences being stronger than indigenous and becoming more so, despite the persistence of nationalism.

This article is the text of the Asian Theatre Journal Lecture, given in New Orleans on 27 July 2007 as part of the Association for Asian Performance Conference, itself part of the Association for Theatre in Higher Education Conference.

Colin Mackerras is Professor Emeritus at Griffith University, Australia. He has written widely on China, especially its theatre and ethnic minorities. His many books and articles on Chinese theatre include The Rise of the Peking Opera (1972) and Chinese Drama: A Historical Survey (1990). He is the China traditional editor for the Encyclopedia of Asian Theatre (2007, ed. Samuel L. Leiter, 2 vols.).
\end{abstract}

I propose to argue that over the last century the history of Chinese drama is, to a large extent, a microcosm of Chinese history, but that politics has had more impact on the drama than the other way around. Despite the rise and continuing importance of nationalism and patriotism in China, change largely inspired from abroad continues to create a major impact on the Chinese theatre, which has accelerated in the last few decades. At the same time, essentially unchanged 
indigenous traditions continue and in some ways are even reasserting themselves. In the long run, it will not surprise me if modernization, by which I mean not colonial modernization but the modernization induced from within China by the reform movement beginning in 1978, proves more injurious to traditions than either colonialism or Marxism-Leninism.

For my point of departure I take the beginning, just a century ago, of the huaju, or "spoken drama." For most of its history huaju has been characterized by performers' use of ordinary speech to convey meaning, as in Western plays, although one account has it that, especially since the 1990s, huaju has lost this emphasis on the spoken word, becoming "more focused on providing a total performance event" (Noble 2007a: 117). Music and song, which dominate in Chinese traditional drama (xiqu), is either totally or nearly absent.

The earliest Chinese huaju is often dated to the first two days of June 1907, when the Spring Willow Society (Chunliu she), set up in February, performed the play The Black Slave's Cry to Heaven (Heinu yutian lu), based on Harriet Beecher Stowe's novel Uncle Tom's Cabin. The venue was actually Tokyo and the model the Japanese "new school" (shinpa) drama. However, famous actor and drama scholar Ouyang Yuqian (1889-1962) regards it as the first real Chinese spoken drama "because before that our country had never had such a well ordered spoken drama script with several acts which we had written ourselves" (Ouyang 1958: 19; see also the discussion in X. Chen 2003: 52-53). What was crucial was that a Chinese troupe performed a Chinese spoken script in Chinese. Later the same year, the Spring Sun Society (Chunyang she) performed the item in Shanghai's Lyric Theatre (Noble 2007a: 112). The play carried a strong social message that sympathized with the downtrodden masses. Edward Gunn points out that The Black Slave's Cry to Heaven also spoke to "the theme of the ethnic Han Chinese determination to overthrow the Manchu minority regime" that currently controlled China "and establish a Chinese republic" (1983: viii).

Apart from the beginnings of huaju, these events give rise to several themes that seem to have been of great importance in the Chinese theatre over the past hundred years. These include a role for drama in society that is highly politicized and drama aimed at affecting society as a whole. Another theme is the tension between a largely foreign-inspired change and a continuity driven by a strong indigenous tradition.

Other than the spoken drama I will note several other forms of drama originating over the last hundred years and, thus, reflecting the extent of change and indeed of foreign influence. One is the geju, "song 
drama." "Inspired by the introduction of Western opera during the New Culture Movement (1916-1920s)" (Zhang 2007: 224), it combines Western and Chinese melodies and musical traditions. Another modern form is wuju, "dance-drama." A kind of performance influenced by ballet, the inaugural large-scale item was The Precious Lotus Lamp (Bao lian deng), premiered in 1957. However, the forms that will loom largest here are those belonging to the broad range of traditional theatres that are now collectively termed xiqu. Among these the most famous genre, and the one "often regarded as the most representative national theatre form" (Mackerras and Wichmann-Walczak 2007: 291), is the jingju, sometimes translated as "Peking opera" or "Beijing opera."

\section{Politics, Revolution, Nationalism}

I return to Gunn's suggestion that oppression in The Black Slave's Cry to Heaven pointed to the suffering of ethnic Han who were trying to regain control of China against the ruling minority Manchu dynasty. The point reminds us that the first and second aims of the manifesto of the Chinese United League (Tongmeng hui), which republican founder Sun Yatsen (1866-1925) set up in August 1905, were "to expel the Manchu barbarians" and to bring back Chinese rule to China, with the establishment of a republic ranking only third, and hostility to Western or Japanese imperialism not figuring at all. ${ }^{1}$ Yet the idea of drama as important for its advocacy of the nation and patriotism was already taking root, and in August 1904 the reformist jingju actor Wang Xiaonong had already put on a new-style piece that aimed to "force people to think and feel for their country" (Karl 2002: 27). ${ }^{2}$

Nationalism was one of the most important forces in republican China. By the time Sun Yatsen reorganized the Guomindang (Nationalist Party) at its First Congress of 1924, he had of course shifted emphasis away from the defeated Manchus and toward opposing imperialism from Japan and the West and promoting the new nation-state. There are differences between Sun Yatsen's conception of nationalism and Chiang Kaishek's, which are beyond the scope of this paper. However, what is clear is that there was a widespread belief that drama could be used to support the Chinese people and nation, especially in opposition to foreign enemies, most importantly Japan. During the Anti-Japanese War (1937-1945), all forms both of traditional and nontraditional drama were used actively in the war effort.

The most explicitly politicized dramas in this period were those produced and performed under the aegis of Talks at the Yan'an Forum on Literature and Art. Speaking in the headquarters of the Chinese Communist Party (CCP) in Yan'an in May 1942, CCP leader Mao Zedong (1893-1976) declared that the political criterion always took 
priority over artistic criteria. In effect, Mao regarded the arts, including drama, as propaganda either for or against the revolutionary cause. During the war, Mao and the CCP put very high and possibly top priority on using drama to defeat Japan, but there could be no question anywhere in the CCP regions of using drama for anything but an explicitly revolutionary purpose.

One factor of great importance in considering change and continuity was the CCP's handling of forms of drama that had originated since the 1911 revolution. The CCP strongly favored the song drama, adapting the local folk "rice-seedling songs" (yangge) to form new items. The most famous yangge piece was the strongly revolutionary The WhiteHaired Girl (Baimao nü), a large-scale piece depicting injustices of landlords toward peasants that premiered in April 1945 in conjunction with the CCP's Seventh National Congress.

The CCP also reformed the traditional drama to suit the needs of the revolution. They took over the form of the "newly written historical drama" (xinbian lishi ju), adapting it for revolutionary purposes. These dramas took themes from before the May Fourth Movement of $1919 ;{ }^{3}$ they were traditional in style, belonging to the jingju or one of the many xiqu forms, but were more complex in scenography and stage properties and had specially written music and scripts that rose to a climax and had a dénouement, quite unlike the episodic structure that had prevailed in the xiqu since the sixteenth century. Mao Zedong saw one of these newly written historical dramas, Driven Up Mt. Liang (Bishang Liangshan), which was based on an incident in the sixteenth century novel Water Margin about the twelfth-century bandit Song Jiang and his followers. It was strongly sympathetic to these rebels against imperial authority who are the novel's heroes. In January 1944 Mao wrote enthusiastic congratulations to two of the authors, who included the director of the performance he saw. "What you have begun is an epoch-making beginning of revolutionizing old traditional theatre," he wrote (trans. in Fei 1999: 142). In other words, Mao still liked the old stories and the old opera, but wanted them reformed and showing support for the revolution.

When Mao and the CCP established the People's Republic of China (PRC), they implemented drama reform throughout the country, roughly in line with Mao's 1942 Talks. In July 1950 the CCP set up its Drama Reform Committee, which immediately held a conference to determine specific directions. Many traditional items were reinterpreted to show the masses in a good light and the ruling class in a negative one. Patriotism was given strong emphasis, and plays that authorities considered to fall short were banned. The government also sponsored revolutionary and politically correct huaju and created a 
new form called wuju, or dance-drama, which was heavily influenced by ballet as promoted through Russian cultural models in the 1950s.

Mao's regime may have censored national ideology, including attitudes toward drama, right from the beginning of his rule, but still favored a reformed tradition. However, with the onset of the Cultural Revolution (1966-1976) we find the flowering of a theory of drama that promoted "model dramas" (yangban xi) that took pride in being propaganda for the CCP, the Chinese revolution, and the revolutionary classes-the workers, peasants, and soldiers. Most of the models were jingju, although there were two ballets and a few nondramatic forms such as symphonies. The traditional costumes, role types, and stage properties of traditional jingju were thoroughly revolutionized to give play to the heroic nature of the revolution and its proponents. By the mid 1970s there were some fifteen of these models, but the trouble was that they excluded everything else, so traditional items were banned and even huaju had to follow the rigid and exclusive themes of the models (Hay 2007: 862-863). These models quickly went out of date with the end of the Cultural Revolution. However, they still have a following and are occasionally performed even now; on New Year's Day 2007 I saw a scene from the "model" ballet The Red Detachment of Women (Hongse niangzi jun) performed at Peking University (Beida) by the China Central Ballet Company (see Plate 1.)

The first years after the Cultural Revolution saw a revival of numerous huaju and items in other forms created from the 1950s and early 1960s. For huaju one emphasis in this period was to express "condemnation of the massive political persecution enforced during the Cultural Revolution" (Yan 1998: x). This was an equivalent in theatre of the "scar literature" (shanghen wenxue) in which CCP writers explored the personal tragedies those years had caused among ordinary people and intellectuals in particular, and even expressed a "nostalgia for the early years" of the PRC (Yan 1998: x).

In May 1977, Driven up Mt. Liang was reperformed after a very long gap, exemplifying the revival of CCP-approved revolutionary dramas on traditional themes and in the form of newly written historical drama. Deng Xiaoping spent the Chinese New Year of 1978 in his home province of Sichuan and there saw several favorite Sichuan operas (chuanju). He gave the actors explicit encouragement to revive these traditional items (see Mackerras 1981: 56-57), and very soon afterward a flood of such performances returned in other provinces.

For jingju the 1980s were a decade of mixed success. On the one hand, the revival of the tradition brought forward some very good newly written historical dramas in the early 1980s. But on the other hand, the decline of audiences and government funding-the lat- 
ter due to reform policies-resulted in serious setbacks later in the decade. Debate over how much of the traditional style and content to preserve, balanced against the need for reform, had an inhibiting effect on dramatists, directors, and actors. The 1989 crackdown on the student movement intensified an already difficult situation for creative innovation in terms of content. One authority writes that "China at the end of the ' 80 s is not an easy ground for the growth of talent and creation in any of the arts, and this is especially true" for jingju (Wichmann 1990: 171).

Under these circumstances, what is perhaps remarkable is that one newly written historical drama did win great popularity both among its target audience, the urban intellectual elite, and with authorities. This was Chen Yaxian's Cao Cao and Yang Xiu (Cao Cao yu Yang Xiu), which premiered in 1988 and was later revised. Though set in the early third century, it is more generally about the relationship between rulers and their ministers, with strong hints that tyrant Cao Cao can be equated with Mao Zedong. Wichmann-Walczak, who saw China as difficult for creation in the arts at the end of the 1980s, declared this item possibly "the most celebrated" jingju since the Cultural Revolution (2005: 62).

The early reform period was very good for the huaju. In 1979, the play Why Did I Die (Wo wei shenma sile) by Xie Min marked the birth of "contemporary avant garde Chinese theatre" (Chen Jide 2004: 19) and it was soon followed by more important and innovative experimental dramas. Among Chinese dramatists of the early reform period, the most prominent is certainly Gao Xingjian. He wrote four highly unconventional plays in the 1980s: Juidui xinhao (Alarm Signal, 1982), Chezhan (Bus Stop, 1983), Yeren (Wild Man, 1985), and Bi'an (The Other Shore, 1986). The first of these was highly critical of society and, though it was not exactly hostile to the CCP, was unprecedented among post-1949 huaju set in the present in more or less ignoring it. ${ }^{4}$ The Other Shore was an attack on collectivism and was criticized as antisocialist, a major factor in Gao's leaving China in 1987. Although Gao was for a time a member of the CCP, he seems to me to represent a category of political drama that is equivocal about the CCP and its ideology or even hostile. In the PRC, this kind of "theatre of resistance" was a phenomenon new to the reform period. Apart from content, Gao's plays were high unconventional in terms of stagecraft, with one authority writing that the spoken drama "appears to be the source of the vast majority of acting and directing innovations" in the 1980s (Wichmann 1990: 158).

Politics and nationalism are still to some extent involved in the theatre of the reform period. Quite a few items have been banned on political grounds, and the authorities still keep an eye out in the the- 
atre for politically incorrect or unpatriotic items. However, it seems to me that, apart from a hiatus of two to three years following the crackdown on the student demonstrations of June 1989, the overall trend has been toward greater freedom, less restrictive politics, and wider variety in the Chinese theatre. More and more what has determined performance has been popular demand, or in many cases the lack of it, and the inventiveness of actors. These comments apply to all forms of theatre, although there are different forces at work in the modern forms, such as huaju, than those operating in the traditional theatre, as I will discuss later in this essay.

\section{Social Reform: Gender}

The idea that drama was a tool for social reform was inherent in the development of the huaju right from the start in 1907 and, in particular, during the New Culture Movement initiated in 1915 and the May Fourth Movement beginning in 1919. Reformers in the decades after 1915 appealed to the theatre, and especially modern forms such as huaju, "In their mission to strengthen China through social reform" (Noble 2007a: 113). Social reform remained a key aim of huaju writers during the genre's acme period and was particularly crucial in the works of China's most distinguished twentieth-century playwright, Cao $\mathrm{Yu}$ (1910-1996). Many consider his powerful tragedy Thunderstorm (Leiyu, 1934) the greatest of all Chinese huaju.

At the same time, the idea of social reform was also found in the $x i q u$, though to a far lesser extent. The famous Mei Lanfang (18941961) was among xiqu actors that introduced social criticism into his work. In 1914, he performed in a long item called Waves of the Sea of Sin (Niehai bolan), which commented on the evils of prostitution and in which the progressive social message was loud and clear.

Perhaps the most important social message throughout the twentieth century was the need to improve the treatment of women and raise their status within society. There were many themes that revolved around this central message. One of them was the right of women to choose their own husbands free of family constraints. It is perhaps not surprising that one of the earliest of the May Fourth plays was the very short The Greatest Event in Her Life (Zhongsheng dashi) by the liberal reformer Hu Shi. Written and set in 1919, it concerns a young woman's determination to choose her own marriage partner, against opposition from her parents.

The CCP also gave some play to the theme of female social status in the pre-1949 period, along with its emphasis on class struggle. The White-Haired Girl, which showed the injustice done to its title character, focused strongly on giving women rights, along with other themes such 
as class struggle and the benefits the CCP had already brought China and would potentially bring in the future.

When the CCP actually came to power, equality for females was one of the policies it emphasized, both in society in general and in the theatre. The message extended both to the modern forms such as huaju and the traditional xiqu. The Conference held by the Drama Reform Committee issued a list of content items that should be banned or promoted. The former included narratives favoring arranged marriages or what the CCP regarded as superstition; the approved works were those pushing for women's and minority rights. The famous 1959 newly written jingju Female Generals of the Yang Family (Yangmen nüjiang) showed that women could excel in the public sphere, even including patriotic military resistance to a powerful enemy.

The model dramas of the Cultural Revolution included several that gave women very prominent roles in the revolution and in society in general. A recent study compares the 1972 model jingju version of Song of the Dragon River (Longjiang song), in which the hero is female, with the earlier 1964 huaju version of the same work, which has a male hero, and finds that the adaptation involved much more than a mere substitution of female for male hero. It "incorporated a multifaceted feminization of the revolutionary hero" and found that the way she carries out her leadership role was "identifiably feminine in the Chinese cultural context” (Roberts 2006: 285).

Probably the most innovative writer for the newly written historical drama in China in the reform period is Wei Minglun (born 1940), who works for the Zigong Municipal Chuanju Troupe in Sichuan Province and writes for various regional forms of xiqu, especially chuanju. Among his numerous works, possibly the best known is Pan Jinlian (1985), which takes up the gender issue through a reevaluation of Pan Jinlian. Pan is a character in a chapter of the novel Water Margin (Shuihu zhuan) as well as in the erotic novel The Golden Lotus (Jin Ping Mei). His traditional reputation is as an evil nymphomaniac who killed one of her husbands and marries Ximen Qing, himself the libertine antihero of The Golden Lotus. Wei's absurdist chuanju brings on witnesses from across history to give evidence about Pan Jinlian. In the end her brother-in-law kills her, as the original story dictates. Various onlookers give their view: Wu Zetian, the only woman in Chinese history to become emperor, finds her "guilty, but not enough to be killed," while Jia Baoyu, hero of A Dream of Red Mansions (Honglou meng) declares, "The root of her guilt lies in social condition!" A female judge of the PRC puts the main responsibility for her fall on "ages of feudalism" but adds that she cannot save her since "we should not follow ways we know are evil” (Wei 1998: 187-188). For Wei Minglun, 
Pan Jinlian is no feminist hero, but the way he shows the various views of her behavior makes for extraordinary drama, a brilliant combination of traditional Chinese theatre and modern Western "absurdism." One of the factors that makes this drama so interesting for me is that although the setting spans so many periods, in fact it seems to be telling us something about women's status in contemporary China and about the extent of personal versus social responsibility for crime, especially as committed by women.

\section{Foreign Inspiration Versus Indigenous Tradition}

Over the last hundred years, the inspiration of foreign theatres on Chinese has been profound. Indigenous theatres survive, and influence between foreign and indigenous has not been entirely one-way or consistent. However, the long-term trend has been in favor of foreign impact.

A very obvious and important example in the technical area is the rising use of the proscenium stage and theatre darkened during performance, as opposed to the traditional stage, which was smaller and in closer proximity to the audience than the modern equivalent, with the spectators often in the open air. The first modern proscenium stage open to Chinese was in the New Stage (Xin Wutai) in Shanghai, which dates from 1908, almost exactly the same time as the birth of huaju. The first in Beijing was built in 1914, with the new Westernized style spreading rapidly from the establishment of the republic in 1912. From the time the CCP came to power in 1949, newly constructed theatres almost all had proscenium stages and were darkened during performance.

The example illustrates that by far the most important among "foreign" theatres are those of the West, but sometimes Japan has formed a bridge, as for example in the origin of the huaju among Chinese students influenced by Japanese shinpa. Another major source of inspiration has been Russia and the Soviet Union. In some respects, it is reasonable to consider Russia and the West together. We may, for instance, note the profound influence the huaju exerted on realism and socialist realism, in playwriting through Anton Chekhov (18601904) and Maksim Gorky (1868-1936) and in acting through Konstantin Stanislavsky (1863-1938). All three inspired the Chinese theatre both directly from Russia itself and indirectly through the influence these artists exerted on the West. Yet in some ways, we cannot simply categorize Russia as part of the West, especially during the Soviet period (1917-1991), which takes up seventy-four of the hundred years under discussion here. For some of that period, Soviet influence on China was extensive and directly hostile to the West.

In considering the interplay of Western influence and Chinese 
tradition in the modern Chinese theatre, it seems to me useful to note the debate over the Sinicization of huaju during this century. We bear in mind three dominant approaches to theatre, which in 1982 Sun Huizhu summarized as the real (zhen), the good (shan), and the beautiful (mei):

If Chekhov and Gorky excelled in depicting realistically "life's undesirable side" in a given society, if Brecht prevailed in using a conspicuously make-believe form of allegory to raise people's consciousness and make them think, then the Chinese traditional theatre prides itself on providing a temporary escape to an idealized realism from a defective real world. (cited in Fei 1999: 177)

As we saw in the previous sections, the idea of plays reflecting realistic society, in accordance with the theory of realism propounded by Norwegian dramatist Henrik Ibsen (1828-1906), Chekhov, Gorky and others, was quite normal from the start of huaju.

There are two main aspects: content and style. Chinese playwrights and theorists were keen to Sinicize huaju to reflect Chinese realities, but they were happy to adopt the realist system of acting that owed its origin especially to Stanislavsky.

In the early years of the PRC, the main opposition to this realism came from the great director Huang Zuolin (1906-1994), longtime vice president, president, and most influential member of the Shanghai People's Art Theatre. In 1962 he gave a major speech in which he called for Chinese huaju to abandon Stanislavsky and the realist models in favor of the conventions of traditional theatre and Brechtian theatre. Huang was a great admirer of the great jingju actor Mei Lanfang, who was for Huang the principal exponent of the Chinese tradition, as Mei had been for the great German director and playwright Bertolt Brecht (1898-1956). Although Huang's ideas were severely criticized during the Cultural Revolution, his influence returned in the 1980s and "his theory eventually helped huaju dislodge itself from Ibsenian-Stanislavskian realism" (S. Liu 2007: 247). In a series of major productions artists showed that realism was not the only possible form for huaju and that the conventions of Chinese traditional theatre could add to the value of contemporary plays. Among productions that showed this, the 1987 China Dream (Zhongguo meng) by Sun Huizhu and Fei Chunfang is an excellent representative example. In the words of Noble, this work "innovatively combines xiqu and gewuju (literally, 'song-dance drama') acting with Brechtian theatrical style to explore the intercultural relationship between an American man and Chinese woman living in the United States" (2007b: 189). An illustrative example of xiqu practice in the play is the way the American John Hodges introduces himself, talk- 
ing directly to the audience, though admittedly the way he does so is different from xiqu. (See also Chen Jide 2004: 75-76).

Modern forms like huaju have coexisted with xiqu, but the xiqu forms have also undergone influence from the West and the Soviet Union. Mei Lanfang introduced not only social criticism but also some realist acting into his work. In the 1914 drama Waves of the Sea of Sin mentioned above, the costumes were contemporary and the acting strongly influenced by realism in contrast to the conventionalism of the jingju.

A contemporary scholar sees the history of jingju over the period 1870 to 1937 in terms of "colonial modernity." He even adopts the Anglicized term "Peking opera" to describe the form, on the grounds that it "bears the traces of colonial modernity, a context of great importance in shaping the genre's identity" (Goldstein 2007: 3). The idea of the newly written historical drama as represented in Driven up Mt. Liang drew inspiration from the West in terms of structure, scenography, and other elements.

The early PRC period and the Cultural Revolution were both anti-Western in their rhetoric, and this bias peaked during the Cultural Revolution, which also added condemnation of the Soviet Union for its "revisionism." However, there were several strongly Western elements in the model dramas. One concrete example was the addition of Western musical instruments in the orchestras of the jingju and other regional styles.

Since the end of the Cultural Revolution the extent of foreign influence on and inspiration of Chinese theatre has strongly increased. Moreover, interest among Chinese in foreign and especially Western theatre has advanced with the number of Western and Russian items performed multiplying. Of course, some of this inspiration has derived very directly from individual playwrights. Among these, the most striking example was probably Arthur Miller, who spent several months in China to direct himself a Chinese-language performance of his Death of a Salesman. With the Chinese title Tuixiaoyuan zhi si, this play premiered on 5 May 1983 and featured the famous Ying Ruocheng (1929-2003) as translator and performer of the antihero Willy Loman. But what is to me most striking is that it is once again Chinese playwrights, directors, and actors who have pushed this Western inspiration. Ying Ruocheng was, after all, vice minister of culture from 1986 to 1990, using his very considerable brilliance and influence to promote collaboration and exchange with the West (see Conceison 2005: 702).

Although he left China for good in 1987, Gao Xingjian can perhaps serve as a good representative of the way Chinese theatre drew inspiration from the West. Chinese living in or loyal to the PRC have 
mixed and dominantly negative feelings about Gao Xingjian for turning his back on his homeland, and they are generally baffled that the Swedish Academy should choose him as the first person writing mainly in Chinese worthy of receiving the Nobel Prize for Literature (Quah 2004: 2-3). Yet he is still generally admired for his cross-cultural work in the 1980s. One PRC writer states that his four 1980s plays assure him of "an irreplaceable position in Chinese avant guard theatre": "He stands at the point where Eastern and Western cultures intersect. Taking in everything and experimenting with determination, he enriched the modes of expression of the huaju art" (Chen Jide 2004: 22). It is of course well known that Gao was deeply influenced by Samuel Beckett (1906-1989), and his play Bus Stop of 1983 took inspiration from the absurdist play Waiting for Godot, though according to Quah (2004: 16), Gao denied that the play is merely a Chinese version of Beckett's original.

Quah has developed a theory of "transculturalism" based on Gao Xingjian, by which he means that Gao's theatre constitutes "a cultural and intellectual sphere in which an interaction of different cultures takes place" (2004: 13). These cultures are not only Chinese and Western. Quah also sees in Gao's work a dialogue between "traditional and modern, literati and folk, mainstream and peripheral" (2004: 13). But we can see in these examples that it is the interplay of Chinese and Western culture that is primary.

Claire Conceison perceives a revival in the Chinese huaju at the end of the twentieth century "after a bleak period during the 1980s and early 1990s," with audiences "younger, wealthier, better educated, and more exposed to Western ideas" (Conceison 2002: 18). Her examples are confined to Shanghai and Beijing, but these are after all China's two most culturally important cities. This renewed enthusiasm for huaju shows increased Western inspiration in terms of performance and content, but also has much to say about Chinese context. Conceison notes two outstanding contributors to this revival: playwright $\mathrm{Yu}$ Rongjun, centered in Shanghai, and director Meng Jinghui, who works in Beijing.

Yu's plays appeal to young people, with their "trendy themes and well-constructed characters" (Conceison 2002: 22). An example of such plays is his highly popular 2000 production www.com, the first Chinese play to deal with the social problems and human alienation associated with the craze for the Internet. It is difficult to think of a more modern, or even post-modern, theme than this one, or one more appropriate to China, given the speed the Internet is growing in importance for young urban Chinese. Meng Jinghui has adapted a range of Western and Soviet plays for the Chinese stage, making West- 
ern inspiration notable in his art. However, Conceison (2002: 24) picks out as his "signature production" an adaptation of Longing for the World (Sifan). An old Chinese story about a Buddhist nun who yearns for love and meets and escapes with a similarly inclined young monk, this was for centuries a favorite theme in kunqu, jingju, and other traditional xiqu styles.

The example takes us from foreign to indigenous inspiration, and we can note that the decades following the Cultural Revolution saw a flourishing both of newly written historical dramas and of revived traditions in the theatre. One Chinese scholar describes the years 1977-1993 as follows: "It embodied perfectly the integration of the traditional and the contemporary. The fact that this integration was so happy and harmonious means that it represents the highest achievement and golden age of New China" (Xie 1995: 6). Actually, the great majority of the items for this period discussed in the book were from the 1980s, which for all the problems was a good period for the newly written historical dramas.

It seems to me that modernization has had a bad impact on the development of xiqu since the 1990s. However, I have seen examples both of traditional items that show some Western inspiration and items in which the preservation of tradition has been very striking.

I will deal with three such experiences in 2006, when I spent a semester teaching at the Beijing Foreign Studies University. The first two were in October and the third in December. All exemplify the persistence of tradition in Chinese theatre, but also show the inroads of modernity.

Early in October I visited Wutai shan, the mountain in Shanxi province famous to Buddhist pilgrims for its wonderful monasteries and spiritual atmosphere. In Wuye Temple at the foot of the mountain I came across a permanent stage where a series of jinju (local Shanxi theatre) was being performed. The stage was directly opposite the image of the god Wuye, the actors telling me that the performances were put on especially for him. They also told me that a festival of local dramas had been going on since May 1 and would finish in mid October, a few days after my visit. The performances sometimes began as early as 3:30 $\mathrm{AM}$, but on the day I attended not until about 9:30 AM. In Wuye's hall opposite the stage was a counter where people were accepting money, some of which was returned to the troupe. The people donating the money had the choice of which dramas the troupe would perform. They also had the privilege of sitting on special chairs placed in the open air opposite the stage. Although the performances were to honor the god, others were welcome to attend, most people sitting on a stone terrace of a nearby hall or on the ground. Apart from the rich who 
patronized the drama, audience members could come and go, most of them doing so after they had paid tribute to Wuye. They could make a donation to Wuye himself, but did not pay for the drama. Several of the monks of the temple were in the audience and obviously enjoying the drama, the content of which was secular and highly traditional. In one place a small boy was shown kowtowing to his mother. A man sitting next to me asked if boys kowtowed to their mother in my country, and then went on to tell me that this was still common in Shanxi, although not nearly as widespread as it used to be.

The social context of this performance was remarkably similar to past patterns. It can be folk amateur troupes that perform on such occasions even now, but the actual performance I attended was given by the Third Shanxi Provincial Jinju Troupe, members of which had come especially from Taiyuan and were staying at a local guesthouse while in Wutai shan. One of the few respects dividing this performance from earlier times was that women played all female roles. I learned from this experience that traditional drama is still quite active in the countryside. (See Plate 2.)

The second experience was a performance of Kong Shangren's (1648-1718) Peach Blossom Fan (Taohua shan), a long kunqu dealing with love and politics that premiered in 1699. The performers were from the Jiangsu Provincial Kunju Troupe (Jiangsusheng Kunju Yuan), and the performances were part of the Ninth Beijing Music Festival. Originally with forty-four scenes, the drama was reduced to six, which were performed over two evenings, with each presentation lasting two hours without interval. In terms of costumes, musical style, and libretto, the arrangers stayed fairly true to the original. However, in contrast to traditional patterns, the orchestra was quite large and had a conductor who stood on a podium. The orchestra members sat at the back of the stage behind a thin screen painted with scenes of Nanjing, where most of the drama is set. The lighting varied according to the action, and, when the stage was dark, the orchestra was very clearly visible.

Although the drama preserved the essence of the tradition, the social context was quite different. The theatre where the performance took place was the Centennial Memorial Theatre in Peking University. The theatre was full on both evenings, and most audience members were students or staff of the university. The revival of Peach Blossom Fan is part of an attempt to give new life to kunqu, which is among the oldest surviving forms of Chinese theatre, dating from the sixteenth century. In 2001, UNESCO added kunqu to its list of Masterpieces of the Oral and Intangible Heritage of Humanity (see Swatek 2007: 356). Significant revivals have included Tang Xianzu's (1550-1616) masterpiece Peony Pavilion (Mudan ting), which was performed as part of the Seventh Beijing Musical Festival in October 2004 (see Figure 1). 


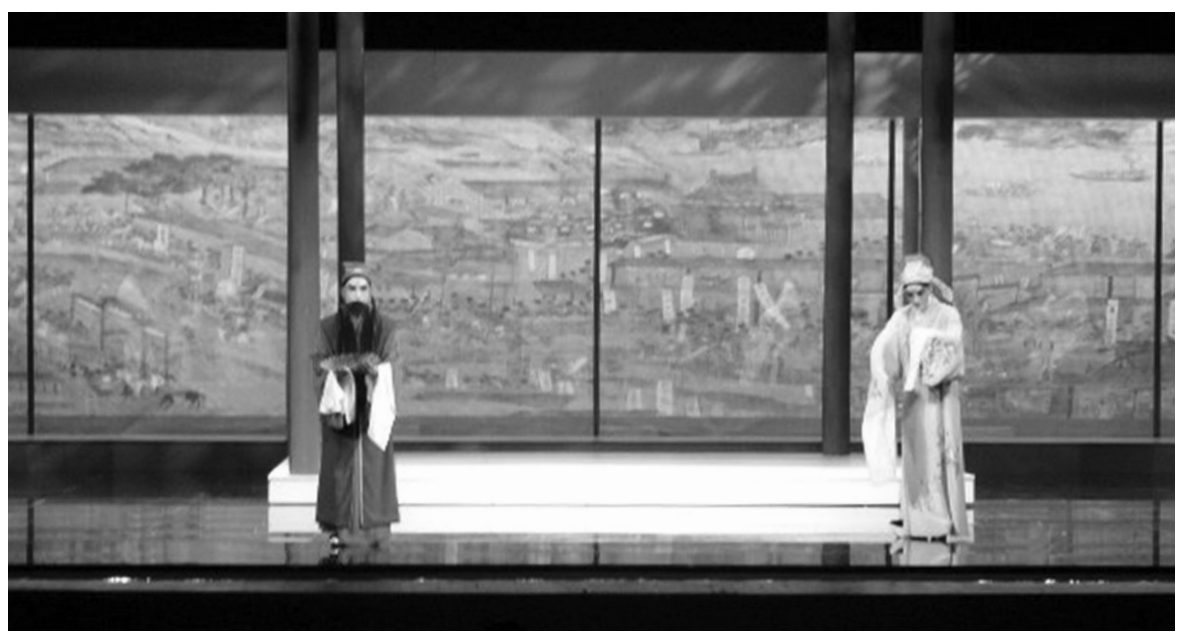

Figure 1. The narrator (left) and lead male role Hou Fangyu (actor Shi Xiaming) in Peach Blossom Fan (Taohua shan), performed in a theatre at Peking University on October 17, 2006 as part of the Ninth Beijing Music Festival. The screen backstage shields the orchestra from view and shows images of Nanjing in the seventeenth century. (Photo: Colin Mackerras)

The third experience was one that has now become very familiar to interested foreigners in Beijing. It is the jingju Havoc in Heaven (Nao tiangong), about Monkey King. Performed in a specially constructed theatre in the Qianmen Hotel in Beijing, it is designed to fulfill two aims: to preserve traditional patterns and to appeal to foreigners and overseas Chinese. The music, singing, acting, costumes, and content are traditional, and Havoc in Heaven exemplifies the complex and thrilling gymnastics found in the jingju. On the other hand, there are modern features. For instance, there are surtitles in English above the stage, and the program is multilingual. Outside the theatre is a clean and modern shop with many products relating to and promoting the traditional Chinese theatre. The target audience is tourists, and the ticket prices are correspondingly expensive. The aim is to help preserve Chinese culture by opening traditional theatre to the large and growing tourist market. (See Figure 2.)

\section{Drama a Microcosm of Chinese History?}

Against this background with some ideas on change and continuity in the Chinese theatre over the last hundred years, I would like to consider the question of how closely the development of theatre reflects changes and continuity in Chinese history itself. To what extent can we see drama as a microcosm of Chinese history itself?

From the beginning we can see some consonance between the 


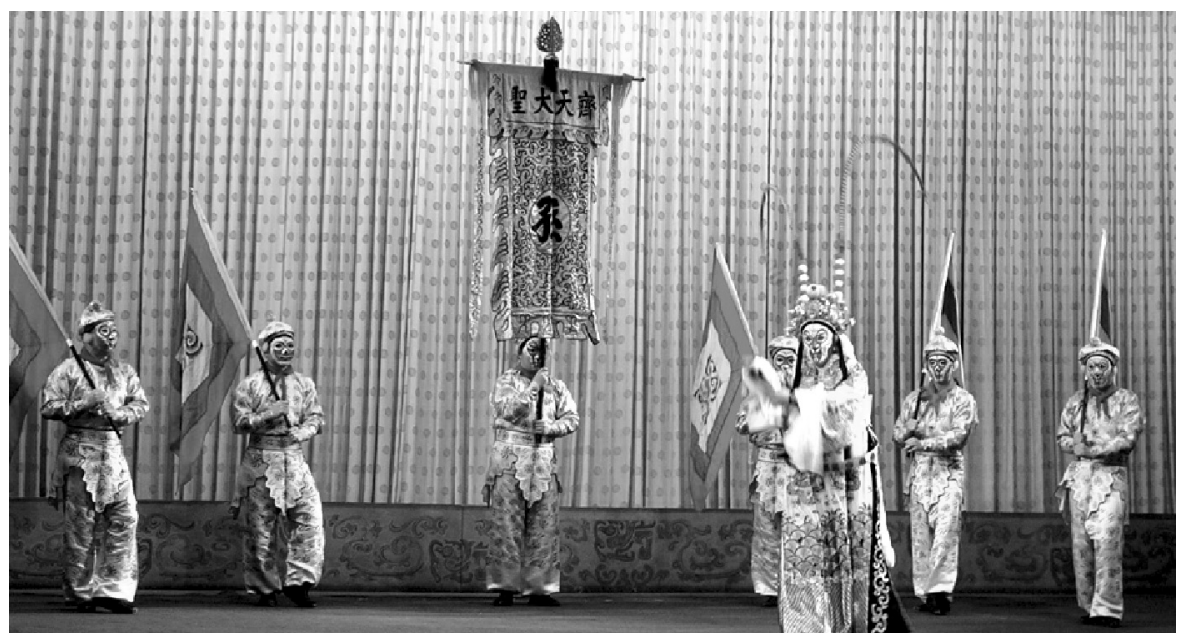

Figure 2. Monkey King's forces prepare for battle in Havoc in Heaven (Nao tiangong), as performed in the tourist theatre at the Qianmen Hotel in southern Beijing. The theatre is designed to copy traditional patterns as well as to suit the needs of international tourists. This item is constantly performed at the theatre, but this particular photograph was taken on 16 December 2006. (Photo: Colin Mackerras)

two. The revolutionary upsurge of the late Qing produced the new drama form of huaju, as well as the social and revolutionary ideas that were embodied in it, and the following decades sharpened the trend. Traditional xiqu clung more to the old ways, certainly, but there were also jingju actors and items that were quite explicit in wanting to reflect the new society. We may not be able to call the new dramas "mainstream," except among progressive intellectuals, but neither was their thinking the mainstream in society at large.

Moving forward to the 1930s and the Anti-Japanese War, we can see that the drama reflected the patriotism of the time. The idea that the arts should function mainly as a means of political propaganda may not have been surprising under the circumstances that prevailed at the time. The strong censorship of theatre in the succeeding period was a component part of the society that followed the establishment of the PRC. There was a certain logic in the fact that, as Mao's insistence on the class struggle became more obsessive in his overall ideology and practice with the onset of the Cultural Revolution, censorship in the theatre became more extreme, possibly the most extreme China has ever seen over its long history. To an unprecedented extent, censorship went beyond merely forbidding specific items to imposing a small number of pieces based on a narrow ideology, banning everything else. 
Since the reforms began in the late 1970s, China has seen a major thrust toward modernization at the very same time as the country has experienced a range of traditional revivals, among which major examples include the powerful return of religions, even including renewed influence of clerics, and the reassertion of certain forms of old family values and patterns. It is my strong impression that these traditional revivals are still not spent, though I would hesitate to cast blanket judgements on this matter. After all, religious revival coexists comfortably with modernity in a range of contexts.

If the reform period evidence is very mixed in China as a whole, it is a bit more consistent in the theatre. In the first period after the Cultural Revolution, all forms of drama, both modern and traditional, experienced a strong revival. But this did not last long. The early 1980s were a boom period for xiqu, including both traditional and newly written historical dramas, but later years saw a decline.

Table 1 shows the numbers of professional state-sponsored performing troupes in selected years from the early 1950s to the early 1990s. It is clear that the 1950s saw a big rise, the early 1960s a decline, and the late 1960s, the height of the Cultural Revolution, a large fall. The great majority of these troupes performed xiqu, not the modern drama forms.

Table 2 shows figures for 1998 and 2005, but these are subdivided by type, showing numbers of huaju and other modern forms, as compared with $x i q u$, including jingju. They show that the overall numbers of performing arts troupes is continuing to decline. The number of xiqu troupes continues to decline sharply, but those of modern forms are rising. Though xiqu troupes outnumber huaju and geju, the

Table 1. Number of arts performing troupes in selected years

\begin{tabular}{lc}
\hline YEAR & ARTS PERFORMING TROUPES (YISHU BIAOYAN TUANTI) \\
\hline 1952 & 2084 \\
1959 & 3504 \\
1966 & 3374 \\
1970 & 2541 \\
1980 & 3533 \\
1985 & 3317 \\
1988 & 2985 \\
1992 & 2753 \\
\hline
\end{tabular}

Sources: State Statistical Bureau 1983: 532; State Statistical Bureau 1993: 777. 
Table 2. Number of drama troupes (figures in parentheses are total staff numbers)

\begin{tabular}{|c|c|c|c|c|}
\hline YEAR & $\begin{array}{c}\text { HUAJU } \\
\text { CHILDREN'S } \\
\text { TROUPES, ETC. }\end{array}$ & GEJU WUJU ETC. & XIQU & $\begin{array}{c}\text { OF WHICH } \\
J I N G J U\end{array}$ \\
\hline 1998 & $88(7,273)$ & $65(7,945)$ & $1562(83,810)$ & $112(10,187)$ \\
\hline 2005 & $118(8,383)$ & $97(9,671)$ & $1531(72,525)$ & $109(7,981)$ \\
\hline
\end{tabular}

Sources: National Bureau of Statistics 1999: 703; National Bureau of Statistics 2006: 861 .

balance between the two is changing significantly in favor of the modern forms.

In the light of all this material, I argue that the history of Chinese drama over the last century is to a large extent a microcosm of Chinese history over the same period. There is no exact congruence, especially in the reform period, but trends in the theatre broadly reflect those in the country as a whole. An interesting question emerges from this: does drama merely reflect the society of its time, or does it influence it?

A recent Chinese work claimed that "expressing the realities of life is an excellent tradition of traditional xiqu" (Gao 1999: 1). It argued further that this had been the case since very ancient times:

We've traced back the tradition whereby traditional theatre reflects the realities of life in order to explain the tight links between xiqu and life. This embodies an artistic rule. Reflecting realistic life was not only the demand of the time and the demand of the audience, it was also the demand of dramatic art itself. But we also need to explain why we've pushed back the history of modern drama several hundred years. It's because in China's long feudal period, although there were changes of dynasty, the basic nature of society and social conditions changed only slowly. (Gao 1999: 14)

But reflecting society is very different from influencing it. The great reformer Liang Qichao (Fei 1999: 109-111) argued that reforming society was impossible without first changing popular literature, including drama, because of the immense influence popular literature exerts over society. Mao Zedong's theory that the arts, including drama, were primarily propaganda certainly implied that theatre exerted a vital influence either for or against the revolution.

The idea of drama as a microcosm of history implies that it both reflects and influences society. However, looking back over the last century, I argue that politics has priority. In other words, the actors and 
dramatists who produced huaju were not operating in a vacuum. They helped an already existing revolutionary process. When Mao Zedong declared the arts as propaganda, he certainly wanted them to help his revolution, but it was a revolution he had already determined to undertake. The modernization program Deng Xiaoping led in the late 1970s profoundly affected the drama, and to some extent the reverse is also true. But it was Deng's politics that took priority, both in terms of time and importance.

\section{Summary and Conclusion}

The last hundred years have seen gigantic changes in the Chinese theatre. The era began with the introduction of the new form the huaju, the centenary of which we are celebrating in 2007. There are other new forms too, such as the geju, or song drama. Even within the xiqu, we find a new slant and genre in the newly written historical dramas. And together with these new forms we find the rise of the proscenium stage and new styles of theatre.

And change is equally obvious when we look at drama from the point of view of content. It would be quite unfair to the old traditional drama to charge it with totally ignoring social problems. But the last hundred years has seen drama used far more than ever before for progressive social purposes, especially raising the status of women. At the same time, we find a totally different slant on using drama for political purposes, including nationalism. A whole range of theories of drama and acting, including realism and absurdism, have been imported from overseas, bringing about extensive change within the very raison d'être of dramatic performance. And these theories have given rise to extensive debate, support, and opposition among Chinese people interested in theatre.

Yet we cannot ignore the areas of continuity either. These include the injection of traditional influences into the new forms, such as attempt to "sinicize" huaju. Traditional dramas and performing troupes may be in decline, but they are certainly not about to die. There have been many interesting attempts to give new life to xiqu forms and to traditional dramas and to revive items not performed for many decades. I have been struck by the way xiqu persists in the countryside among folk troupes, even when state-sponsored professional troupes appear to be in decline.

The conclusion is that, over the last hundred years, change outweighs continuity by a wide margin. The current decline of tradition is probably due more to the latest stage in modernization, which is China-induced, rather than due to the colonial modernization of the pre-1949 period or Marxism-Leninism. 
It seems natural to associate change more with outside influence than with indigenous factors. It is easy to point to phenomena that originated from outside, but were then adopted in China. They include the proscenium stage, the new theories like realism, and new theatre techniques such as the scenography of the newly written historical dramas. There is considerable irony here, because it was a tide of antiimperialism that brought these novelties from abroad. And in the first half of the twentieth century it was the same progressive movements that attacked traditional theatre as part of the dross of the old society and that resulted in slogans like "down with Confucius and sons!"

There may be various evaluations of how Chinese theatre has fared over the past hundred years under the influence of so much change. There are quite a few successes and accomplishments, such as the careers of Mei Lanfang and other great actors and of playwrights such as Cao Yu. There also areas in which we might wish things had been different, such as the extreme censorship that prevailed during the Cultural Revolution. I do not actually see much point in casting judgments. But I do think that change is likely to go on outweighing continuity in the Chinese theatre over the coming decades. And I also suspect that it will continue to be broadly, though not precisely, a microcosm of Chinese social development as a whole.

\section{NOTES}

1. See a translation of much of the Manifesto in Mackerras 1998: 9798.

2. Called Guazhong lanyin (literally, "melon seeds, cause of the orchid"), the item was about an ostensible war between Poland and Turkey that resulted in Poland's humiliation and partition. The actual message concerned the Russo-Japanese war, fought on Chinese soil but not involving China.

3. According to Liu Naichong (1983: 512), "The scope of subject matter" of the newly written historical dramas "includes history from the period of high antiquity down to before the May Fourth Movement."

4. The French newspaper Le monde declared Gao Xingjian's Juedui xinhao (Absolute Signal, 1982) to be the beginning of avant-garde theatre in China (Quah 2004: 63)

\section{REFERENCES}

Chen Jide. 2004.

Zhongguo Dangdai Xianfeng Xiju, 1979-2000 (Contemporary Avant Garde Theatre in China). Beijing: Chinese Theatre Press. 
Chen, Xiaomei. 2003.

"Introduction." In Reading the Right Text, An Anthology of Contemporary Chinese Drama, edited by Xiaomei Chen. Honolulu: University of Hawai'i Press.

Conceison, Claire. 2002.

"Hot Tickets, China's New Generation Takes the Stage." Persimmon: Asian Literature, Arts, and Culture 3, 1: 18-27.

2005.

"Ying Ruocheng." In Encyclopedia of Contemporary Chinese Culture, edited by Edward L. Davis. London: Routledge.

Fei, Faye Chunfang, ed. and trans., foreword by Richard Schechner. 1999.

Chinese Theories of Theater and Performance from Confucius to the Present. Ann Arbor: University of Michigan Press.

Gao Yilong. 1999.

"Xulun: Fanying Xianshi Shenghuo Shi Chuantong Xiqu de Chuantong" ("Introduction: Reflecting Realistic Life Is a Tradition of Traditional Drama"). In Zhongguo Xiqu Xiandai Xi (Modern Plays in Chinese Traditional Drama), ed. by Gao Longyi, Li Xiao, et al. Shanghai: Shanghai Culture Press.

Goldstein, Joshua. 2007

Drama Kings, Players and Publics in the Re-creation of Peking Opera, 18701937. Berkeley: University of California Press.

Gunn, Edward M. 1983.

"Introduction." In Twentieth-Century Chinese Drama: An Anthology, ed. by Edward M. Gunn. Bloomington: Indiana University Press.

Hay, Trevor. 2007.

"Yangban xi." In Encyclopedia of Asian Theatre, edited by Samuel L. Leiter. Vol. 2. Westport, CT: Greenwood Press.

Karl, Rebecca E. 2002.

Staging the World, Chinese Nationalism at the Turn of the Twentieth Century. Durham, NC: Duke University Press.

Liu Naichong, 1983.

"Xinbian Lishi Ticai Jumu" (Newly Written Dramas on Historical Themes). In Zhongguo Da Baike Quanshu, Xiqu Quyi (China Encyclopedia, Traditional Drama and Story-telling), ed. by Zhang Geng, Zhao Jingshen, Wang Jisi, Ma Yanxiang, Guo Hancheng, Tao Dun, et al. Beijing: China Encyclopedia Press.

Liu, Siyuan. 2007.

"Huang Zuolin (1906-1994)." In Encyclopedia of Asian Theatre, ed. by Samuel L. Leiter. Vol. 1. Westport, CT: Greenwood Press.

Mackerras, Colin. 1981.

The Performing Arts in Contemporary China. London: Routledge and Kegan Paul. 1998.

China in Transformation 1990-1949. London: Longman. 
Mackerras, Colin, and Wichmann-Walczak, Elizabeth. 2007.

"Jingju." In Encyclopedia of Asian Theatre, ed. by Samuel L. Leiter. Vol. 1. Westport, CT: Greenwood Press.

National Bureau of Statistics, People's Republic of China. 1999.

Zhongguo tongji nianjian China Statistical Yearbook 1999. Beijing: China Statistics Press.

2006.

Zhongguo tongii nianjian China Statistical Yearbook 2006. Beijing: China Statistics Press.

Noble, Jonathan. 2007a.

"China: Modern Theatre." In Encyclopedia of Asian Theatre, ed. by Samuel L. Leiter. Vol. 1. Westport, CT: Greenwood Press.

. 2007b.

"Experimental Theatre: China." In Encyclopedia of Asian Theatre ed. by Samuel L. Leiter. Vol. 1. Westport, CT: Greenwood Press.

Ouyang Yuqian. 1958.

"Huiyi Chunliu" (Looking Back on Spring Willow). In Zhongguo huaju yundong wushi nian shiliao ji, diyi ji (Collection of Materials on Fifty Years of the Chinese Spoken Drama Movement, First Collection), ed. by Tian Han, Ouyang Yuqian, et al. Beijing: Chinese Theatre Press.

Quah, Sy Ren. 2004.

Gao Xingjian and Transcultural Chinese Theater. Honolulu: University of Hawai'i Press.

Roberts, Rosemary. 2006.

"From Zheng Qiang to Jiang Shuiying: The Feminization of a Revolutionary Hero in Maoist Theatre's Song of the Dragon River." Asian Theatre Journal 23, 2: 265-291.

State Statistical Bureau. 1983.

Zhongguo tongji nianjian 1983 (Statistical Yearbook of China 1983). Beijing: China Statistics Press.

1993.

Zhongguo tongji nianjian 1993 (Statistical Yearbook of China 1993). Beijing: China Statistics Press.

Swatek, Catherine. 2007.

"Kunqu." In Encyclopedia of Asian Theatre, ed. by Samuel L. Leiter. Vol. 1. Westport, CT: Greenwood Press.

Wei Minglun. 1998.

"Pan Jinlian, The History of a Fallen Woman," trans. by David Williams, with the assistance of Xiaoxia Williams. In Theater and Society: An Anthology of Contemporary Chinese Drama, ed. by Haiping Yan. Armonk, NY: M. E. Sharpe.

Wichmann, Elizabeth. 1990.

"Tradition and Innovation in Contemporary Beijing Opera Performance," The Drama Review. Spring 34 (1): 146-178. 
Wichmann-Walczak, Elizabeth. 2005.

"Cao Cao and Yang Xiu." In Encyclopedia of Contemporary Chinese Culture, ed. by Edward L. Davis. Abingdon, UK: Routledge.

Xie Bailiang. 1995.

Zhongguo Dangdai Xiqu Wenxue Shi (History of the Literature of Contemporary Chinese Traditional Drama). Beijing: Chinese Social Sciences Press.

Yan, Haiping, 1998.

"Theater and Society, An Introduction to Contemporary Chinese Drama." In Theater and Society: An Anthology of Contemporary Chinese Drama, ed. by Haiping Yan. Armonk, NY: M. E. Sharpe.

Zhang, Nan. 2007.

"Geju." In Encyclopedia of Asian Theatre, ed. by Samuel L. Leiter. Vol. 1. Westport, CT: Greenwood Press. 